Revue Revue de l'histoire des religions

del'histoire des religions

4| 2021

La magie entre Antiquité et Moyen Âge : traditions, innovations, autorités

Liesbeth CORENS, Confessional Mobility and English Catholics in Counter-Reformation Europe

Oxford/New York, Oxford University Press, 2019

Mathilde Monge

\title{
OpenEdition
}

Journals

Édition électronique

URL : https://journals.openedition.org/rhr/11610

DOI : $10.4000 /$ rhr. 11610

ISSN : 2105-2573

Éditeur

Armand Colin

Édition imprimée

Date de publication : 1 décembre 2021

Pagination : 764-767

ISBN : 978-2-200-93378-4

ISSN : 0035-1423

Référence électronique

Mathilde Monge, "Liesbeth Conens, Confessional Mobility and English Catholics in Counter-Reformation Europe », Revue de l'histoire des religions [En ligne], 4 | 2021, mis en ligne le 01 décembre 2021, consulté le 06 janvier 2022. URL : http://journals.openedition.org/rhr/11610 ; DOI : https://doi.org/10.4000/rhr. 11610

Ce document a été généré automatiquement le 6 janvier 2022

Tous droits réservés 


\section{Liesbeth CORENS, Confessional Mobility and English Catholics in Counter- Reformation Europe}

Oxford/New York, Oxford University Press, 2019

\section{Mathilde Monge}

\section{RÉFÉRENCE}

Liesbeth CORENS, Confessional Mobility and English Catholics in Counter-Reformation Europe, Oxford/New York, Oxford University Press, 2019, 240 p., 70,56 €, 23,4 cm,

ISBN 978-01-9881-2432.

1 Parmi les nombreuses diasporas de l'époque moderne, celle des catholiques britanniques est une des plus complexes. Confessionnal Mobility traite d'une partie de cette diaspora, celle des Anglais, de manière convaincante et informée. Le livre de Liesbeth Corens est lauréat du prix du Reformation Research Consortium (RefoRC) 2019. Le format ramassé de l'ouvrage, version remaniée d'une thèse de l'université de Cambridge, n'obère pas sa qualité, dans la mesure où les références y sont réellement européennes. L'auteure mobilise en effet une bibliographie francophone, germanophone et néerlandophone, point trop rare dans les travaux de langue anglaise.

2 L'ouvrage saisit la communauté catholique anglaise dans un des moments les moins traités de leur histoire, la période 1660-1720, et se concentre sur l'Angleterre, les PaysBas espagnols et sur la France du Nord - ces deux derniers territoires formant une unité culturelle. Le titre, "La mobilité confessionnelle», est une prise de position: l'auteure s'inscrit en faux par rapport à l'historiographie traditionnelle des minorités religieuses déplacées à l'époque moderne. Dans ces dernières, la migration et l'installation hors du pays d'origine sont représentées comme un exil, donc comme un déplacement définitif, rompant avec le pays d'origine et vécu comme un déchirement. En outre, dans cette historiographie, comme dans les études migratoires, l'inscription 
du migrant dans la sphère sociale du pays d'origine et dans celle du pays d'accueil est trop souvent dissociée. L. Corens prend donc acte d'évolutions très récentes dans la recherche sur les Britanniques sur le continent, comme les travaux de Douglas Catterall ou Ciaran O'Scea. Confessionnal mobility parvient à mobiliser une documentation et des méthodologies variées pour montrer que c'est le confessionnel, justement, qui fait des Anglais catholiques en Europe une communauté dispersée. En effet, dans le contexte de la fin du XvII esiècle anglais, celui de la Glorieuse Révolution (1688) qui réveille l'hostilité au catholicisme, les catholiques anglais fondent leur inscription communautaire sur leur situation minoritaire dans un monde pluriconfessionnel où les guerres de religion ont reculé au profit d'autres modes d'affrontement.

3 L'ouvrage se structure autour de différentes figures: "L'exilé », "Le fugitif », "Le pèlerin ", "Le voyageur en quête d'éducation ", "L'intercesseur » et "L'archiviste et l'historiographe ». Il ne s'agit pourtant pas d'une approche prosopographique, mais d'une manière plutôt élégante et dynamique de donner sens à une documentation très dispersée, aussi bien dans sa nature que dans la couverture des différents espaces considérés. Paradoxalement, alors que l'auteure s'intéresse majoritairement aux laïcs, la documentation se trouve dans les archives des établissements religieux, surtout féminins, les plus nombreux à s'être exilés après la suppression des ordres religieux par Henri VIII en 1534. Elle est complétée par de nombreuses correspondances (parfois provenant d'archives privées) et par des ouvrages de piété, pour beaucoup apologétiques. La littérature secondaire, récente, est également abondamment mobilisée, si bien que l'ouvrage apparaît comme une recherche originale faisant le lien entre de nombreux travaux par ailleurs disparates. Si la scansion des trois parties structurant le livre (Distance, Mobilité, Orientation) n'est pas des plus convaincantes, les chapitres en leur sein permettent d'exploiter les différentes figures de la mobilité, laissant de côté une logique chronologique qu'il serait difficile de tenir. En outre, et c'est une des forces de l'ouvrage, l'auteure opère dans certains chapitres une comparaison pied à pied avec la diaspora réformée en Europe, sur la base d'une historiographie récente. Ces deux populations, comparées même par Pierre Bayle dans son Avis aux Réfugiés, se sont en effet croisées dans toute l'Europe du Nord et aux colonies. Elle souligne par exemple que les deux groupes considéraient la mobilité de manière très différente : alors que pour les protestants, la fuite était la répétition de la fuite en Égypte et le signe d'élection d'une Église souffrante, pour les catholiques la mobilité était rapportée aux missions apostoliques d'une Église catholique dont la domination devait être partout réinstaurée.

4 Ainsi, Liesbeth Corens réconcilie au moins deux champs historiques en général peu enclins au dialogue, celui des études migratoires et celui de l'histoire religieuse. Le propos de l'ouvrage est bien de montrer comment les catholiques anglais forment une communauté transnationale, voire trans-locale - l'auteure n'utilise pas ce terme pourtant à la mode dans les études migratoires, telle qu'il a été défini par Clemens Greiner et Patrick Sakdapolrak. La mobilité, parce qu'elle était répétée, vécue, et interprétée par les catholiques anglais comme étant inscrite dans une communauté de chrétiens persécutés au sein de l'Église catholique, faisait d'eux une communauté dispersée et trans-locale, qui se concevait comme à la fois en Angleterre et sur le continent. Le cas des pèlerinages l'illustre. La chapelle de Notre-Dame-de-Montaigu dans le Brabant est particulièrement prisée des Anglais, qui lui ont consacré de nombreuses publications. Ils s'y rendaient en pèlerinage et préservaient des objets de dévotion faits du chêne associé au culte. L'élection de ce lieu particulier trouve son 
origine dans une histoire et une iconographie marquée par la résistance aux assauts des soldats protestants. D'une manière générale, les voyages des catholiques anglais sur le continent étaient souvent émaillés d'une retraite dans un des nombreux couvents du continent. Les nombreuses confréries et sodalités, dont les membres pouvaient se trouver sur tout le continent, unissaient le groupe et donnaient une dynamique grâce aux échanges entre les membres et aux flux financiers - c'est le cas par exemple de la confrérie du rosaire des Dominicains anglais, qui comptait des membres aussi bien dans les Pays-Bas espagnols qu'en Angleterre.

5 L'auteure ambitionne par ailleurs de réintégrer les catholiques anglais dans l'histoire générale du catholicisme, comme des fers de lance de la Contre-Réforme. Loin d'être secondaires dans une histoire qui a longtemps été écrite à l'aune romaine, ils en sont au contraire parmi les plus ardents promoteurs, cultivant l'ardeur missionnaire de leur jeunesse et la ferveur religieuse en situation de clandestinité. L'ouvrage traite des «marginaux » à plus d'un titre d'ailleurs. Non seulement il s'intéresse principalement aux laïcs (même si les religieux des nombreux couvents ont un rôle central), mais il fait également la part belle aux femmes, indispensables dans la préservation d'un catholicisme devenu essentiellement domestique dans les îles Britanniques. La circulation des reliques, souvent originaires d'Angleterre (comme celles de saint Chad, transportées à Saint-Omer et à Gand) dans l'espace de la diaspora, restaure les liens entre ses différents membres. Les catholiques anglais travaillent ainsi activement à perpétuer leur vénération et à consolider l'Église en Europe. Elles sont également « une part importante de l'arsenal dans la mission de conversion", avec les indulgences qui leur sont associées (p. 154). Les nombreux voyageurs anglais qui arpentent le continent sont tour à tour étudiants, occupés à un "Grand Tour » ou bien en retraite spirituelle dans un des nombreux couvents. Beaucoup passent par Rome, ou au moins par les PaysBas espagnols, bastions du catholicisme contre-réformateur, et nombre d'entre eux expérimentent une conversion, concevant le voyage comme un itinéraire spirituel et promouvant ainsi un approfondissement de la foi et un renforcement de la communauté dispersée, selon les modèles tridentins.

6 Le livre de Liesbeth Corens, bien écrit, pourvu d'un utile index, illustré de reproductions de gravures et de photographies d'objets de dévotion, réussit ainsi pleinement dans son ambition de réintégrer une diaspora, par ailleurs bien connue, aux dynamiques du XvII ${ }^{\mathrm{e}}$ siècle européen.

\section{AUTEURS}

\section{MATHILDE MONGE}

Université Toulouse 2 - Jean-Jaurès. 